\title{
Correction to: Delivering PrEP to Young Women in a Low-Income Setting in South Africa: Lessons for Providing Both Convenience and Support
}

Tali Cassidy ${ }^{1,2}$ - Nelisiwe Ntuli ${ }^{1}$. Charllen Kilani ${ }^{1} \cdot$ Nikiwe Malabi $^{1} \cdot$ Bulelwa Rorwana $^{1} \cdot$ Tabitha Mutseyekwa $^{1}$. Rebecca O'Connell ${ }^{1}$ - Sarah Jane Steele ${ }^{3} \cdot$ Zibusiso Ndlovu $^{3} \cdot$ Tom Ellman $^{3} \cdot$ Virginia de Azevedo $^{4} \cdot$ Colin Pfaff $^{1}$. Aurelie Nelson ${ }^{1} \cdot$ Laura Trivino Duran ${ }^{1}$

Published online: 24 July 2021

(c) Springer Science+Business Media, LLC, part of Springer Nature 2021

\section{Correction to: AIDS and Behavior https://doi.org/10.1007/s10461-021-03366-X}

The original version of this article unfortunately contained an error. One of the co-author names is misspelled.

Zee Ndlovu should read Zibusiso Ndlovu.

The authors would like to correct the error with this erratum.
Publisher's Note Springer Nature remains neutral with regard to jurisdictional claims in published maps and institutional affiliations.

The original article can be found online at https://doi.org/10.1007/ s10461-021-03366-x.

Tali Cassidy

talicassidy@gmail.com

Nelisiwe Ntuli

msfocb-khayelitsha-endtb@brussels.msf.org

Charllen Kilani

charllenkilani@gmail.com

Nikiwe Malabi

msfocb-khayelitsha-hivdata2@brussels.msf.org

Bulelwa Rorwana

rorwana.b@gmail.com

Tabitha Mutseyekwa

MSFOCB-Khayelitsha-Prep@brussels.msf.org

Rebecca O'Connell

rebocon@gmail.com

Sarah Jane Steele

sarahjane.steele@joburg.msf.org

Zibusiso Ndlovu

Zee.NDLOVU@joburg.msf.org
Tom Ellman

Tom.ELLMAN@joburg.msf.org

Virginia de Azevedo

vafdeazevedo@gmail.com

Colin Pfaff

MSFOCB-Khayelitsha-med@brussels.msf.org

Aurelie Nelson

aurelie.nelson@googlemail.com

Laura Trivino Duran

trivinoduran@yahoo.com

1 Médecins Sans Frontières, Cape Town, South Africa

2 Division of Public Health Medicine, School of Public Health and Family Medicine, University of Cape Town, Cape Town, South Africa

3 Southern African Medical Unit, Cape Town, South Africa

4 City Health Department, Cape Town, South Africa 